\title{
DEPLOYMENT AND OPERATION OF THE ES-3100 TYPE B SHIPPING CONTAINER
}

\author{
Jeffrey G. Arbital \\ HEU Disposition Program Office \\ BWXT Y-12, LLC \\ Oak Ridge, Tennessee, USA
}

\author{
Dean R. Tousley \\ Office of Fissile Materials Disposition \\ National Nuclear Security Administration
}

\author{
Dennis B. Miller \\ HEU Disposition Program Office \\ BWXT Y-12, LLC
}

\begin{abstract}
The U.S. Department of Energy (DOE) National Nuclear Security Administration (NNSA) is shipping, for disposition purposes, bulk quantities of fissile materials, primarily highly enriched uranium (HEU). The U.S. Department of Transportation (DOT) specification $6 \mathrm{M}$ container has been the workhorse for NNSA and many other shippers of radioactive material since the 1980s. However, the 6M does not conform to the packaging requirements in the Code of Federal Regulations (10 CFR 71) and, for that reason, is being phased out for use in the DOE secure transportation system by the end of 2006. BWXT Y-12 developed and licensed the ES-3100 container to replace the DOT 6M. The ES-3100 was certified by the Nuclear Regulatory Commission (NRC) in April 2006. The process of deploying the new package began in June 2005 and is planned to be completed in July 2006. The package will be fully operational and completely replace the DOT $6 \mathrm{M}$ at the Y-12 National Security Complex (Y-12) by October 2006.
\end{abstract}

This paper reviews the deployment process and the mock loading station that was installed at National Transportation Research Center (NTRC) of Oak Ridge National Laboratory. Specialized equipment, tools, and instrumentation that support the handling and loading operations of the ES-3100 are described in detail. Loading options for other user sites are explored in preparation for deployment of this new state-of-theart shipping container throughout the DOE complex and the private sector.

\section{KEYWORDS}

Shipping Package, Radioactive Material Transportation, Type B Fissile Packaging, Licensing, Regulatory Compliance, Fissile Mass Loadings, Packaging Operations

\section{INTRODUCTION}

The shipment of material is a significant element of the HEU disposition activities under the NNSA fissile materials disposition program. DOT $6 \mathrm{M}$ containers are currently the package of choice for most of these HEU shipments. However, since the $6 \mathrm{M}$ container is not licensed, DOE has decided to phase out the use of the $6 \mathrm{M}$ for type B shipments - i.e., on the DOE Safe-Secure Trailer (SST) and Safeguards Trailer (SGT) systems. As a result of the phaseout of the DOT 6M, the HEU Disposition Program needed a new package for the shipment of Type B quantities of HEU. The answer to this need became the ES-3100 development program.

This new Type $\mathrm{B}$ radioactive material shipping package has been licensed by NRC. The package is now in the final stages of full-scale deployment, and operations will begin in the fall of 2006. A mock-up loading station was created at the NTRC for use in equipment check-out and operator training. New tools and equipment were developed for the ES-3100, but only a few are very specialized, and most could be employed for other shipping packages. The intent was to make the packaging operation more user-friendly than in the past and take this opportunity to employ state-of-the art techniques to a process that has been in place for over 20 years.

$\begin{array}{cl}\text { NOMENCLATURE } \\ \text { CFR } & \text { Code of Federal Regulations } \\ \text { CoC } & \text { Certificate of Compliance } \\ \text { CV } & \text { containment vessel } \\ \text { DOE } & \text { U.S. Department of Energy } \\ \text { DOT } & \text { U.S. Department of Transportation } \\ \text { HAC } & \text { hypothetical accident conditions }\end{array}$




$\begin{array}{ll}\text { HDPO } & \text { HEU Disposition Program Office } \\ \text { HEU } & \text { highly enriched uranium } \\ \text { NCT } & \text { normal conditions of transport } \\ \text { NNSA } & \text { National Nuclear Security Administration } \\ \text { NRC } & \text { U.S. Nuclear Regulatory Commission } \\ \text { NTRC } & \text { National Transportation Research Center } \\ \text { SAR } & \text { Safety Analysis Report } \\ \text { SGT } & \text { Safeguards Trailer } \\ \text { SST } & \text { Safe-Secure Trailer } \\ \text { Y-12 } & \text { Y-12 National Security Complex }\end{array}$

\section{DESCRIPTION OF THE ES-3100}

The design of the ES-3100 is similar to that of other shipping packages currently being designed at Y-12. This Type B package has two major systems, a drum assembly and a containment assembly. For the ES-3100 (Fig. 1), the drum assembly consists of an outer drum, insulation, an inner liner, and a top plug. The containment assembly consists of a pressure vessel (commonly referred to as a containment vessel or CV) and an O-ring seal. The components of the package also include the top insulation plug, drum lid, silicone pads, content cans, and neutron absorber spacers.

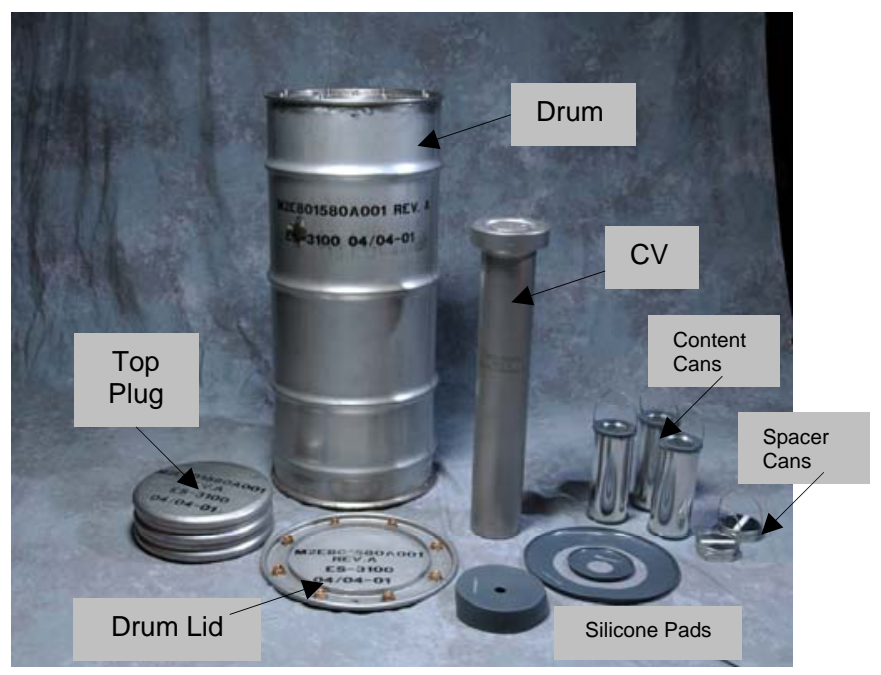

Figure 1. ES-3100 Container

\section{Drum Assembly}

The primary function of the drum assembly is to ensure that the $\mathrm{CV}$ and its contents remain confined under both Normal Conditions of Transport (NCT) and Hypothetical Accident Conditions (HAC) as defined in 10 CFR 71 [1]. For HAC, the ES-3100 package must be able to withstand the rigors of not only a 30 -ft drop and a 40 -in. puncture test but also a dynamic crush. The dynamic crush test, as defined in the recently finalized changes to 10 CFR 71 , consists of dropping an 1100-lb steel plate from $30 \mathrm{ft}$ onto the package in its most vulnerable orientation.

The current design employs a modified 30-gal military standard, stainless steel, drum about 19 in. outside diameter and
44 in. tall. The modifications include the attachment of angle iron at the top of the drum. The angle iron serves as a place for weld studs to be attached as well as an anchor for the inner liner. Another modification has to do with a unique drum bottom attachment, which will reduce deformation during structural testing.

A key design feature of the ES-3100 drum assembly is the use of a fully encapsulated insulation material. It should be noted that while it is referred to as insulation material, this material provides energy absorption during drop, crush, and puncture testing as well as thermal insulation during thermal testing. The use of an inner liner attached to the drum with angle iron creates an annular space, which is subsequently filled with an insulating material. The ES-3100 uses a fireproof insulation called Kaolite $1600^{\mathrm{TM}}$ in the encapsulation zone. Kaolite $1600^{\mathrm{TM}}$ is a mixture of Portland cement and expanded vermiculite [2].

Under HAC conditions, the moisture within the Kaolite $1600^{\mathrm{TM}}$ is vaporized to steam, which then escapes from the package via vent holes in the drum. This results in heat dissipation and more protection of the containment boundary O-ring seals. The drum inner liner becomes a heat transfer barrier (convection and radiation) during the HAC, keeping the temperature around the containment boundary close to $212^{\circ} \mathrm{F}$.

Another significant feature of the drum assembly is a neutron absorbing system. The neutron absorbing system uses a cast material in an annular section on the inside wall of the drum liner. This neutron absorber is a noncombustible, cast material manufactured by the Thermo Electron Corporation (Catalog No. 277). The material is a high alumina concrete mixed with over $6.0 \mathrm{wt} \%$ natural boron carbide $\left(\mathrm{B}_{4} \mathrm{C}\right)$. The material also entrains moisture for moderation and thus enhanced neutron capture. The presence of this neutron absorber allows increased fissile mass loadings over other Type $B$ packages. The use of a neutron absorbing layer in a drumtype package is a new concept, and the ES-3100 is the first package of its kind to be licensed.

\section{Containment Boundary}

The primary function of the $\mathrm{CV}$ is to maintain containment of the radioactive materials being shipped. This is accomplished through the use of a stainless steel vessel body and lid with an elastomeric O-ring seal (Fig. 1). To comply with 10 CFR 71 requirements, whole body leak rates must hn maintained under NCT and HAC scenarios. For uranium materials, for which the ES-3100 is primarily being designed, whole body leak rates on the order of $1 \times 10^{-4} \mathrm{ref}-\mathrm{cm}^{3} / \mathrm{s}$ must be maintained during NCT. However, for materials with greater specific activity $(\mathrm{Ci} / \mathrm{g})$, such as plutonium, this leak rate often is required to be as low as $1 \times 10^{-7} \mathrm{ref}-\mathrm{cm}^{3} / \mathrm{s}$. The lower leak rate is achievable with the current design, and this was demonstrated in the Safety Analysis Report (SAR) for this package [3]. The ES-3100 CV is designed to operate with an internal pressure of $100 \mathrm{psig}$ and has been manufactured in accordance with the ASME B\&PVC, Section III, Subsection 
NB [4] since it is designated a Category I vessel per NRC Regulatory Guide 7.11.

The sealing mechanism for the ES-3100 CV involves a single nut that engages a threaded flange on the CV body. This single nut applies pressure to the top lid, thus providing adequate pressure on the O-rings to maintain a seal. A torque of $115 \mathrm{ft}-\mathrm{lb}$ is required to completely engage the nut. The CV body of this package, the upper threaded region, and the unique lid sealing mechanism are illustrated on Fig. 2.

A key design feature of the ES-3100 is the size of the CV. Both the diameter and height of the CV have been optimized for bulk HEU shipments while also taking into account the size of plutonium containers. As a general-purpose, criticality-safe container, a CV diameter of 5 in. was chosen. The use of such a diameter limits the opportunities for loading other parts, but other packages exist for shipment of intact parts larger than 5 in. The ES-3100 conceptual design specifies a 5.06-in. inside diameter $\mathrm{CV}$ (with a tolerance of \pm 0.04 in.). There is clearance outside the $\mathrm{CV}$ of this configuration to allow for a slightly larger CV for other applications.

For payload efficiency, the overall height of the CV has been designed at $31.5 \mathrm{in}$. (inside height). This height allows for the loading of up to three 10-in.-tall content cans or six 4.75in.-tall content cans, including allowances for packaging materials such as spacers (1-in.-thick neutron absorber between content cans) and plastic bagging. This height results in a 50\% increase in content loading over the current DOT 6M container.

\section{REGULATORY COMPLIANCE}

The ES-3100 package complies with the NRC requirements in 10 CFR 71 and with the International Atomic Energy Agency requirements (TS-R-1) [5] for international Type B shipments. The following are specific safety requirements that should be stressed in the new design:

- Meet all regulatory requirements, including a sequential drop and dynamic crush test.

- Ease of certification, relying on state-of-the-art, but defensible, technology and experience in licensing Type B packages.

A SAR was submitted for NRC review on March 1, 2005. The submittal requested the certification of the ES-3100 package with bulk HEU contents and issuance of a Type B Fissile Material Certificate of Compliance (CoC). The SAR submittal demonstrated that the ES-3100 package with bulk HEU contents meets the applicable requirements of 10 CFR 71 and 49 CFR 100-178 [6]. To protect the health and safety of the public, shipments of radioactive materials made in the ES3100 are assured to be safe because the package has been designed, fabricated, assembled, tested, procured, used, maintained, and repaired in accordance with the regulations cited above. General safety requirements that will be met are containment of radioactive materials, radiation shielding, and assurance of nuclear subcriticality. 
The ES-3100 package passed the verification process (analysis, similarity comparisons, tests, or a combination of these) for NCT and HAC. Full-scale packages were used for design verification testing. The ES-3100 package with bulk

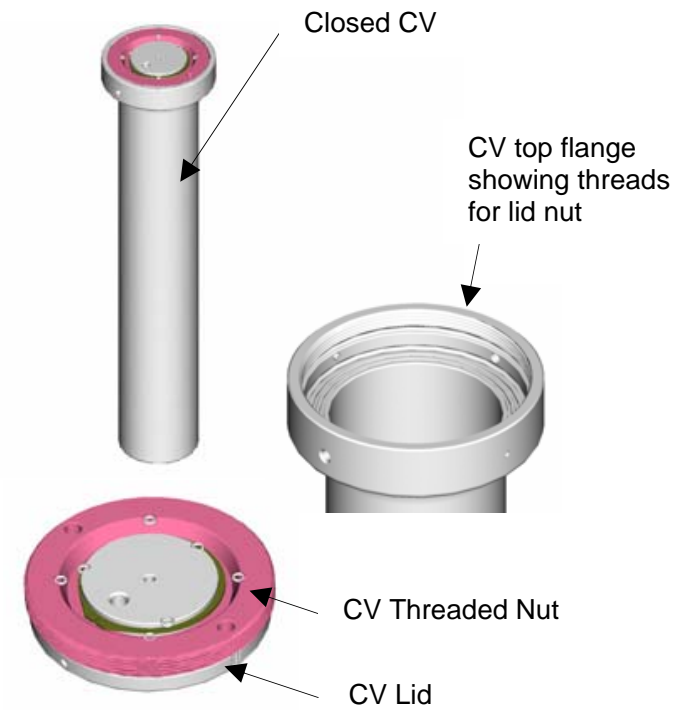

Figure 2. Containment Vessel Details

HEU content was verified solely on the ability of the package to meet the requirements of 10 CFR 71 and 49 CFR 100-178. The influence of the transport vehicle on the package is not accounted for in complying with regulations.

\section{AUTHORIZED CONTENTS}

The ES-3100 license specifies bulk HEU contents only. The HEU forms in the license application are oxide $\left(\mathrm{UO}_{2}, \mathrm{UO}_{3}\right.$, or $\mathrm{U}_{3} \mathrm{O}_{8}$ ), uranium metal and alloy (bulk broken pieces, ingots, buttons, or small castings), and uranyl nitrate crystals (UNX). The ES-3100 package has been designed to physically accommodate a maximum of $24 \mathrm{~kg}$ of HEU oxide or UNX crystals and a maximum of $36 \mathrm{~kg}$ of HEU metal and alloy. The maximum weight of contents (HEU and content cans) is $40.9 \mathrm{~kg}(90 \mathrm{lb})$. The maximum concentrations of the uranium isotopes requested for these forms in the ES-3100 package are listed in Table 1.

In the future, other materials will be added as authorized contents of the ES-3100 on a case-by-case basis. There is speculation that plutonium oxide contents will be added, as well as other transuranic isotopes and fission product isotopes. The mass loading and configuration of these other potential contents in the ES-3100 will have to be determined by analyses and can not be estimated at this time.

Table 1. Concentration Limits for U Isotopes in Contents

\begin{tabular}{|c|c||}
\hline Uranium isotope & Limit \\
\hline $\mathrm{U}-232$ & $0.040 \mu \mathrm{g} / \mathrm{gU}$ \\
\hline $\mathrm{U}-233$ & $0.006 \mathrm{~g} / \mathrm{gU}$ \\
\hline
\end{tabular}

\begin{tabular}{||l|l||}
\hline $\mathrm{U}-234$ & $0.02 \mathrm{~g} / \mathrm{gU}$ \\
\hline $\mathrm{U}-235$ & $1.00 \mathrm{~g} / \mathrm{gU}$ \\
\hline $\mathrm{U}-236$ & $0.40 \mathrm{~g} / \mathrm{gU}$ \\
\hline $\mathrm{U}-238$ & $1.00 \mathrm{~g} / \mathrm{gU}$ \\
\hline
\end{tabular}

\section{Mass Loadings}

Mass loading limits for fissile material in various content forms have been determined by extensive criticality analyses. The total allowable mass loading of package contents is $36 \mathrm{~kg}$ per package, but the fissile component (U-235) is less than that amount as dictated by criticality analysis. The fissile mass loadings for the ES-3100 content forms are given in Table 2.

Table 2. Fissile Mass Loading Limits (per Package)

\begin{tabular}{||l|l|l|l||}
\hline Content & Enrichment & CTI $^{\mathbf{b}}$ & Uranium Loading \\
\hline Spheres $^{\mathrm{a}}$ & $\leq 100 \%$ & 0.0 & $32.938 \mathrm{~kg}^{235} \mathrm{U}$ \\
\hline Cylinders $^{\mathrm{a}}$ & $\leq 100 \%$ & 0.0 & $18.000 \mathrm{~kg}^{235} \mathrm{U}$ \\
\hline Square Bars $^{\mathrm{a}}$ & $\leq 100 \%$ & 0.0 & $30.000 \mathrm{~kg}^{235} \mathrm{U}$ \\
\hline Slugs $^{\mathrm{a}}$ & $>80 \%$ & 0.0 & $16.342 \mathrm{~kg}^{235} \mathrm{U}$ \\
\hline Slugs $^{\mathrm{a}}$ & $\leq 80 \%$ & 0.0 & $26.213 \mathrm{~kg}{ }^{235} \mathrm{U}$ \\
\hline Broken metal $^{\mathrm{a}}$ & $>95 \%, \leq 100 \%$ & 2.0 & $11.097 \mathrm{~kg}{ }^{235} \mathrm{U}$ \\
\hline Broken metal $^{\mathrm{a}}$ & $>90 \%, \leq 95 \%$ & 2.0 & $16.703 \mathrm{~kg}{ }^{235} \mathrm{U}$ \\
\hline Broken metal $^{\mathrm{a}}$ & $>80 \%, \leq 90 \%$ & 2.0 & $15.834 \mathrm{~kg}{ }^{235} \mathrm{U}$ \\
\hline Broken metal $^{\mathrm{a}}$ & $>70 \%, \leq 80 \%$ & 2.0 & $23.734 \mathrm{~kg}{ }^{235} \mathrm{U}$ \\
\hline Broken metal $^{\mathrm{a}}$ & $>60 \%, \leq 70 \%$ & 2.0 & $24.692 \mathrm{~kg}{ }^{235} \mathrm{U}$ \\
\hline Broken metal $^{\mathrm{a}}$ & $\leq 60 \%$ & 2.0 & $35.320 \mathrm{kgU}$ \\
\hline Oxides $^{\mathrm{c}}$ & $>20 \%, \leq 100 \%$ & 0.0 & $21.124 \mathrm{~kg}{ }^{235} \mathrm{U}$ \\
\hline UNX crystals $^{\mathrm{c}}$ & $>20 \%, \leq 100 \%$ & 0.0 & $11.303 \mathrm{~kg}{ }^{235} \mathrm{U}$ \\
\hline \hline
\end{tabular}

a. Mass loading limits are based on a spacer between each content can. Spacers are 4 in. diameter $\times 1.7$ in. thick, fabricated from neutron absorbing material.

b. Criticality Transport Index. Different CTIs have been used in calculations for broken metal contents, with varying effects on allowable fissile mass per package [3].

c. Total mass limit is $24 \mathrm{~kg}$.

\section{Physical Forms}

Solid uranium contents of specific geometries are defined as follows:

1. Spheres are no larger than 3.24 in. diameter: maximum of two spheres per can.

2. Cylinders are no larger than 3.24 in. diameter: maximum of one cylinder per can.

3. Square bars are no larger than 2.29 in. $\times 2.29$ in. (cross section): maximum of one bar per can. 
4. $\underline{\text { Slugs }}$ are 1.5 in. diameter $\times 2.0$ in. tall: maximum of ten slugs per can, where the actual number permitted is restricted by the stated mass loading limit.

Broken uranium metal contents are in random, unspecified geometric forms and other shapes not covered by solid geometric forms. For pyrophoric considerations, broken uranium metal to be shipped in the ES-3100 must meet the following characteristics:

1. Pyrophoric forms, such as uranium metal powders, foils, turnings, and wires shall not be shipped unless the materials pass the following broken metal size restriction tests.

Broken metal pieces should be of a size that (1) the specific surface area does not exceed $50 \mathrm{~cm}^{2} / \mathrm{g}$ and (2) will not pass freely through a mesh size 8 sieve $(2.38 \mathrm{~mm}$ or $0.0937 \mathrm{in}$.). Other tests to determine pyrophoricity of the uranium metal contents may be used at the shipper's discretion.

2. Incidental small particles and samples (those which do not pass the size restriction tests in No. (1), including foils, turnings, or wires, may be shipped with the original batch but are restricted to $<1 \%$ by weight of the content batch.

Uranium oxide contents include $\mathrm{UO}_{2}, \mathrm{UO}_{3}$, and $\mathrm{U}_{3} \mathrm{O}_{8}$. The physical form of oxide is typically dense, loose powder that may contain clumps. Water content of all oxides is limited to $3 \mathrm{wt} \%$. Theoretical densities of $\mathrm{UO}_{2}, \mathrm{U}_{3} \mathrm{O}_{8}$, and $\mathrm{UO}_{3}$ are $10.96 \mathrm{~g} / \mathrm{cm}^{3}, 8.30 \mathrm{~g} / \mathrm{cm}^{3}$, and $7.29 \mathrm{~g} / \mathrm{cm}^{3}$, respectively. Actual working densities are expected to be significantly less.

UNX crystals are formed by dissolving uranium metal or any of the uranium oxides in nitric acid. It crystallizes from solution as the well-formed crystal $\mathrm{UNX}\left[\mathrm{UO}_{2}\left(\mathrm{NO}_{3}\right)_{2} \bullet \mathrm{XH}_{2} \mathrm{O}\right.$, where $\mathrm{X} \leq 6]$. The theoretical density of UNX crystals is $2.79 \mathrm{~g} / \mathrm{cm}^{3}$; however, the working density is expected to be significantly less.

\section{CONTENT CANS AND BOTTLES}

The contents of the ES-3100 package are typically contained in a "convenience" can or bottle. The typical content cans include: stainless and carbon steel cans, nickel cans, polyethylene bottles, and Teflon bottles. The cans/bottles are strictly for the convenience of the operator and are restricted only by size and mass of off-gassing materials that are allowed in the CV. The total off-gassing material allowed in the CV of the ES-3100 is limited to the value in the CoC, currently $500 \mathrm{~g}$ total. Polyethylene bags are included under this limit.

\section{SHIPMENT CAPACITIES}

For most Type B shipments, the ES-3100 will be shipped in an SGT. For ease of loading the SGT, pallets may be used to handle multiple packages. An SGT pallet will hold six ES-3100 packages in a single layer. Considering the maximum weight of the loaded ES-3100 packages, as many as 5 loaded pallets or 30 packages can be carried in an SGT.

\section{PACKAGE OPERATIONS}

The ES-3100 was designed to be loaded and unloaded while the CV is either inside or outside the drum. The decision on which of these two methods to use is site-specific and will depend on site criticality, shielding, and other safety concerns. Special tools have been designed at Y-12 to aid in the operation of the package. In addition, a custom leak test device has been developed for the ES-3100, although it can be used on any leak-testable shipping package. Other users may need to design their own tool sets.

\section{Loading the CV While Outside Drum}

One option for loading the ES-3100 package is with the $\mathrm{CV}$ external to the drum. The CV is lifted out of the overpack
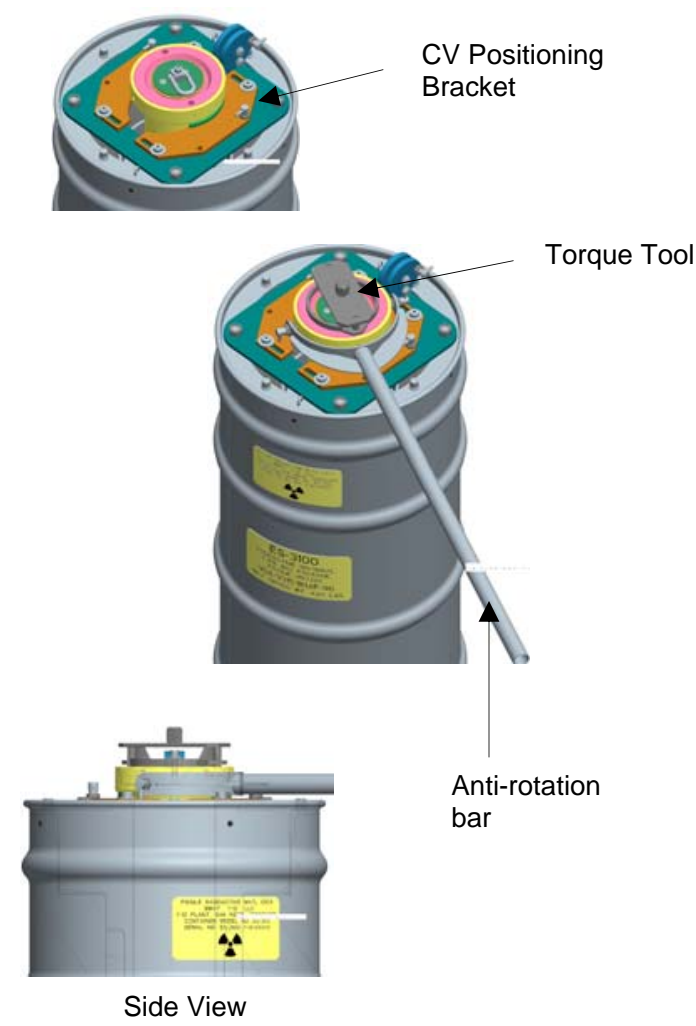

Figure 4. Loading Inside the Drum

drum and mounted on an anti-rotation fixture. The anti-rotation device allows high torque to the closure nut while preventing the $\mathrm{CV}$ from spinning. The required tightening torque on the $\mathrm{CV}$ closure nut is $120 \mathrm{ft}-\mathrm{lb}$.

Special tools for this operation include a bench-mounted (anti-rotation) holding fixture and a lid tightening tool. Figure 3 shows the holding fixture with a CV mounted and a tightening tool engaged to the lid nut. The lifting eye arrangement is shown separately; it is used for handling the $\mathrm{CV}$, by hoist, outside the drum. The photograph in Fig. 3 depicts a content can being lowered into a ES-3100 CV. 

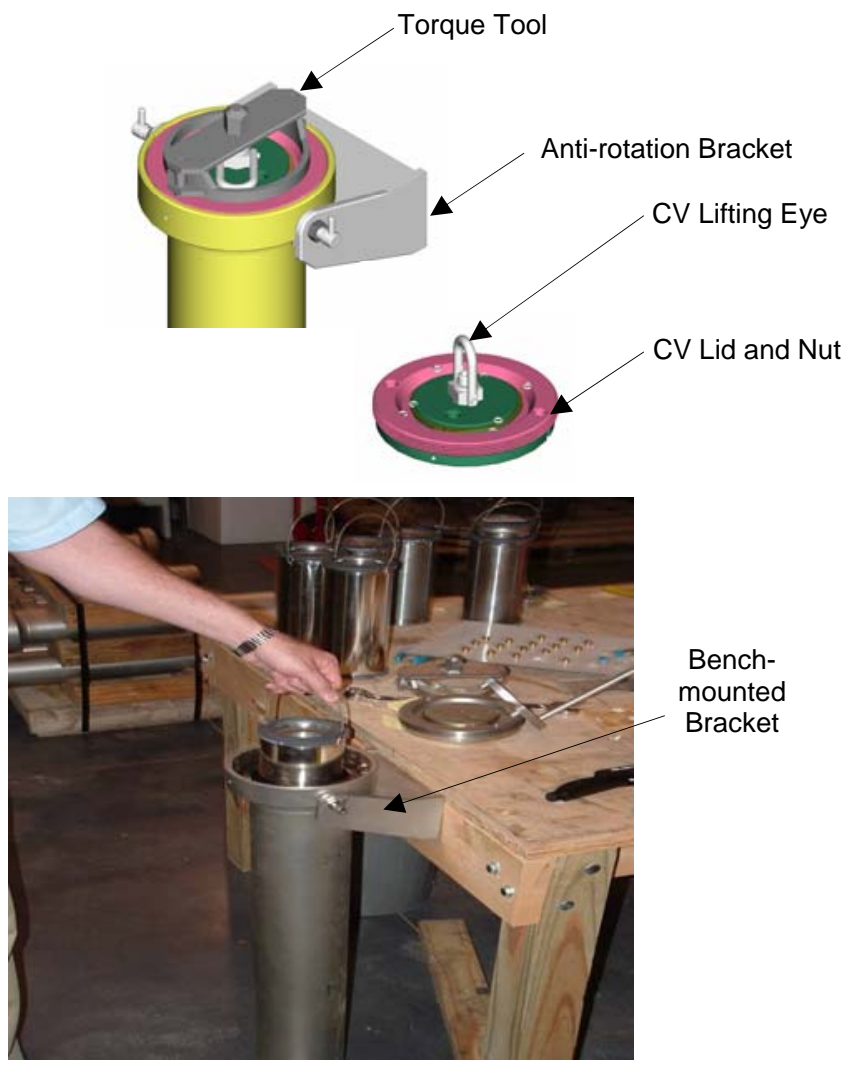

Figure 3. Loading Outside the Drum

\section{Loading the CV While Inside Drum}

The second option for loading the ES-3100 is with the CV internal to the drum. User sites that are concerned about criticality issues may want the $\mathrm{CV}$ inside the neutron absorber while fissile material is contained in the $\mathrm{CV}$.

The tool set designed at Y-12 for this operation is depicted on Fig. 4. The tools include a device that holds the top flange of the CV just above the top lip of the drum so that the CV flange can be engaged with an anti-rotation device (shown as a pipe tool). To achieve this positioning, the CV is lifted only a few inches with the use of a lifting eye attached to the lid. Once lifted, the $\mathrm{CV}$ is then engaged by the (removable) fixture that holds it in place. For this operation, a pipe tool is the antirotation device, allowing the $\mathrm{CV}$ lid to be loosened and tightened.

\section{Leakage Testing}

Leakage testing, specified in ANSI N14.5-1997 for Type B shipping packages, is conducted to establish that an acceptable preshipment (post-load) leakage rate is achieved for the ES-3100. The preshipment (post-load) leakage rate test on the ES-3100 can be a standard pressure rise test using air as the test gas. The area of concern for the test is the annulus between the two O-rings in the CV flange. Typical leak test equipment should have at a minimum a vacuum pump, absolute pressure transducer, air compressor, and certified reference volume. The acceptance leakage rate after loading the ES-3100 should be $1 \times 10^{-4} \mathrm{ref}-\mathrm{cm}^{3} / \mathrm{s}$.

\section{DEPLOYMENT ACTIVITIES}

The ES-3100 is operated in accordance with NRC, DOT, and other federal, state, and local regulations to protect the health and safety of the public, workers, and the environment. The ES-3100 must be operated in accordance with a quality assurance plan. All users should develop detailed site-specific operating procedures based on the ES-3100 SAR and the NRC-issued $\mathrm{CoC}$, as well as a site-specific packing station. These procedures shall be in accordance with Subparts A, G, and $\mathrm{H}$ of 10 CFR 71, and other NRC, DOT, federal, state, and local regulations as cited above. The package operations should be consistent with maintaining occupational radiation exposures as low as reasonably achievable as required by 10 CFR 20.1101, "Standards for Protection Against Radiation."

The user of the ES-3100 shall:

1. Have authorization to acquire, package, transport, or transfer radioactive, fissile, or special nuclear material.

2. Have the latest NRC CoC and referenced SAR for the ES-3100 package with authorized contents.

3. Comply with all actions and restrictions specified in the CoC.

4. Be registered with NRC as a user of the package. 
5. Have a quality assurance program that meets the requirements of $10 \mathrm{CFR} 71$, Subpart $\mathrm{H}$.

The ES-3100 packing station tooling should be manportable and easily configured to address space limitations. The tooling consists of a leak tester and a transport dolly capable of lifting, weighing, and transporting the ES-3100 container. A lifting device on the dolly allows manipulation of the $\mathrm{CV}$ and the material cans to facilitate safe and ergonomic packing and unpacking while maintaining criticality safety. A torque multiplier may be used to remove and attach the $\mathrm{CV}$ closure nut, and reduce the reliance on anti-rotation devices for the $\mathrm{CV}$.

\section{TRANSITION THE ES-3100 SYSTEM}

Initial operations of the ES-3100 will be at several facilities that support DOE programs. The first uses will be at Y-12, Washington Savannah River Company, Nuclear Fuel Services, and BWXT Lynchburg.

Other sites interested in using the ES-3100 can get specific information from the author. The following types of technical assistance are available for potential ES-3100 user sites:

1. Prototype ES-3100s can be obtained for use in developing procedures and loading station designs.

2. Specialized tool sets can be obtained for use in developing procedures.

3. Operating conditions are outlined in the SAR.

4. Leak test equipment specifications are available to determine applicability of existing equipement.

5. The ES-3100 package can be acquired directly from a licensed vendor.

6. License amendment requests to add contents to the authorization basis of the ES-3100 will be handled by Y-12 Engineering.

\section{DISCLAIMER}

This report was prepared as an account of work sponsored by an agency of the United States Government. Neither the United States Government nor any agency thereof, nor any of their employees, makes any warranty, express or implied, or assumes any legal liability or responsibility for the accuracy, completeness, or usefulness of any information, apparatus, product, or process disclosed, or represents that its use would not infringe privately owned rights. Reference herein to any specific commercial product, process, or service by trade name, trademark, manufacturer, or otherwise, does not necessarily constitute or imply its endorsement, recommendation, or favoring by the United States Government or any agency thereof. The views and opinions of authors expressed herein do not necessarily state or reflect those of the United States Government or any agency thereof.

\section{REFERENCES}

[1] U.S. Nuclear Regulatory Commission, Title 10, Code of Federal Regulations, Part 71, "Packaging and Transportation of Radioactive Material," Washington, DC, 2004.

[2] Byington, G. B., Oakes, Raymon E., Jr., Feldman, M. R., U.S. Patent, "Fireproof Impact Limiter Aggregate Packaging Inside Shipping Containers," Patent No. US 6,299,950 B1, US Patent Office, Washington, DC, October 9, 2001.

[3] BWXT Y-12, Safety Analysis Report, Y-12 National Security Complex, Model ES-3100 Package with Bulk HEU Contents, Y/LF-717, Oak Ridge, Tennessee, February 25, 2005.

[4] American Society of Mechanical Engineers, "Rules for Construction of Nuclear Power Plant Components," Sect. III, Div. 1, Subsection NB, ASME Boiler and Pressure Vessel Code, An American National Standard, New York, NY, 2002.

[5] International Atomic Energy Agency, Regulations for the Safe Transport of Radioactive Material, TS-R-1, Vienna, Austria, 1996.

[6] U.S. Department of Transportation, Title 49, Code of Federal Regulations, Parts 100-178, "Transportation," Washington, DC, 2004. 